\title{
Patrícia Ponte
}

Doutora em Geografia, Docente da Licenciatura em Geografia

do Instituto Federal da Bahia - Campus Salvador

patriciaponte@ifba.edu.br

\section{Ver, ser e estar nas paisagens: trajetórias de um conceito em abertura}

\begin{abstract}
Resumo
"A paisagem não é feita para se olhar". Essa afirmação de Eric Dardel, em seu livro O Homem e a Terra, originalmente publicado na década de 1950, vai de encontro, de forma muito à frente de sua época - e até mesmo dos dias atuais -, do que comumente - e geograficamente - se entende por paisagem. Embora muitas décadas tenham se passado desde essa publicação, pouco parece ter ficado dessa concepção de paisagem nos estudos geográficos, até mesmo se consideramos as produções da geografia humanista, campo que mais se apropriou da obra do geógrafo francês. Ao afirmar que a paisagem não é feita para se olhar, Dardel rompe com a herança da visualidade pictórica atribuída ao termo e que perpassou, seguindo diferentes caminhos, a construção teórica desse conceito na ciência geográfica. O que é paisagem, o que há na paisagem, então, além do que vemos? Essas são questões que buscaremos explorar no presente artigo, a partir de uma revisão das trajetórias da paisagem na geografia e suas atuais aberturas.
\end{abstract}

Palavras-chave: paisagem, visualidade, olhar, experiência.

\begin{abstract}
SEEING, BEING AND BEING IN LANDSCAPES: PATHWAYS OF AN OPENING CONCEPT

"The landscape is not made to look at". This statement by Eric Dardel, in his book L'Homme et la Terre, originally published in the 1950s, disagrees, far ahead of his time - and even today - rather than commonly - and geographically -, with what has been meant by landscape. Although many decades have passed since this publication, little seems to have been left of this conception of landscape in
\end{abstract}


geographical studies, even if we consider the productions of humanistic geography, a field that best appropriated the work of the French geographer. By asserting that the landscape is not made to look at, Dardel breaks with the inheritance of the pictorial visuality attributed to the term and that has run through, following different paths, the theoretical construction of this concept in geographical science. What is landscape? So, what is in the landscape beyond what we see? These are questions that we will seek to explore in this paper, from a review of landscape pathways in geography and its current openings.

Key-words: landscape, visuality, look, experience.

\section{A visualidade perpassa a paisagem: trajetórias de um conceito}

Entender por que ao afirmar que "a paisagem não é feita para se olhar"11 Eric Dardel se coloca tão à frente do seu tempo perpassa pela compreensão da história desse conceito na geografia, suas heranças e percursos. Faz-se necessário, até mesmo, voltarmos à paisagem antes da ciência geográfica, visando a compreender como sua etimologia consolidou e perpetuou o elemento da visualidade como central - no senso comum e na ciência -, assim como também permitiu, na constituição do conceito na geografia, a existência de uma constante dualidade, entre o cenográfico e o que estaria além ou seria anterior ao que se vê. Sobre essa dualidade falaremos mais adiante nesse trabalho.

Nesse sentido, Denis Cosgrove (2004) reafirma a importância da compreensão das origens do termo paisagem e de suas mudanças de significado ao longo da história como um importante caminho para o entendimento das formas de pensar o espaço (desde antes do surgimento da geografia científica moderna até a contemporaneidade). As origens do que entendemos hoje como paisagem advém das palavras Landschaft e landscape, nos vocábulos alemão e inglês, respectivamente. Landschaft surgiu primeiro, na Idade Média, e designava uma porção de terra delimitada pelos costumes e cultura de uma comunidade, como explica Cosgrove, citando Kenneth Olwig:

O que importava para a designação é que estas eram regiões em que a lei costumeira, determinada de várias formas pela vida e pelo trabalho da comunidade em uma área, definia os limites territoriais da região [Land]. "Costumes e cultura definiam a região [Land], não características geográficas físicas - era uma entidade 
social que encontrou a sua expressão física na área sob a sua lei". A unidade da comunhão e direitos dentro da comunidade e o espaço sobre o qual eles se estendiam constituíam a Landschaft (2004, p. 60)².

Aspectos cênicos ou pictóricos, muito associados às paisagens até hoje, eram pouco relevantes nas distinções visíveis de uma Landschaft para outra. Para Cosgrove, elas apontam primeiramente para o sentido de uma "espacialidade particular em que uma área geográfica e sua aparência material são constituídas através de prática social” (2004, p. 61). Em face dessa densidade de significações, é compreensível que o autor considere como uma perda o advento da sua correspondente anglo-saxã, landscape, cujos significados alteram de forma considerável o sentido até então estabelecido na Alemanha. A palavra landscape surge na língua inglesa no início do século XVII, designando um tipo de pintura específico (landscape painting). Daí a origem do seu sentido cênico, que remete a cenário. Tecnicamente, o advento desta paisagem pictórica alinhava-se à atividade de elaboração de mapas, visto que compartilhavam uma "linguagem espacial" baseada na matemática e no advento da perspectiva. Aqui, Cosgrove tece uma crítica ao predomínio do aspecto visual dessa paisagem e cita os desdobramentos prejudiciais ao sentido espacial do conceito:

Como essas várias associações sugerem e a palavra "perspectiva" deixa claro, a paisagem [landscape] privilegia o sentido da visão, e o que começou como uma representação do espaço tornou-se rapidamente uma denominação do próprio espaço material, que foi referido como paisagem e visto com o mesmo olhar distanciado e esteticamente exigente que tinha sido treinado na apreciação de imagens e mapas. A paisagem é vista, seja enquadrada dentro de um desenho ou pintura, composta dentro das bordas de um mapa, ou vista a partir de uma eminência física através de recuos de perspectiva (2004, p.61)33.

Ainda segundo o autor, essa concepção representou a modernização do termo paisagem, que passa a designar uma área aferida e delimitada a partir de técnicas científicas de medição, distância, levantamento geométrico e perspectiva linear. Além do sentido espacial, o sentido social da paisagem também se altera na passagem de Landschaft para landscape. Enquanto a primeira vinculava-se à ideia de comunidade local e suas próprias regulamentações, advindas de hábitos e práticas ancestrais, a segunda estava mais próxima da ideia de propriedade, regulamentada pela legislação. Essa ressignificação da paisagem teve um papel importante na 
construção dos direitos de propriedade capitalistas, que suprimiam exatamente o tipo de regulação local característico da Landschaft. Landscape fazia parte de um discurso e da política nacional inglesa cujo projeto político era baseado na expulsão das comunidades de suas terras. A paisagem pictórica foi utilizada para naturalizar e criar uma ilusão harmônica de espaço nacional (COSGROVE, 2004, p. 62).

Essa naturalização da paisagem, segundo Jean-Marc Besse (2014a, p. 106), é ideológica, com fins de naturalizar as desigualdades das relações sociais, ocultando a realidade dos processos históricos e dos conflitos que os produziram, funcionando como um "controle visual e estratégico" (2014a, p. 107). De acordo com o autor, as diferenças de significações são fundamentais, enquanto significação principalmente estética ou enquanto significação geográfica e territorial. Enquanto, na primeira acepção, a paisagem seria "a extensão de um território que se descortina num só olhar", valorizando a vista abarcada por determinados sujeitos (BESSE, 2014, p. 21), na segunda, ela seria mais um espaço objetivo de existência, num sentido jurídico-político, determinado por um conjunto de propriedades humanas e naturais.

Uma questão importante levantada por Holzer (1999, p. 152) refere-se às possíveis diferenciações no significado de paisagem nas línguas alemã e francesa, já que Alemanha e França viriam a constituir as duas principais escolas da geografia. Landschaft e paysage possuiriam equivalência linguística? O autor acredita que não, visto que a primeira, além de mais antiga, tem um sentido mais abrangente e complexo que o das línguas latinas, nas quais o termo é renascentista e mais relacionado a um gênero específico de pintura, assim como no caso de landscape (mesmo que sua raiz linguística esteja associada ao termo holandês - landschap, equivalente ao termo alemão -, o sentido a aproxima mais da paisagem como representação pictórica). No entanto, o mesmo autor afirma que a apropriação da palavra paysage pela geografia francesa a destituiu do seu sentido renascentista, atribuindo-lhe um sentido similar ao do termo alemão, a partir da associação da palavra ao seu radical - pays, que na Idade Média significava tanto habitante como território (HOLZER, 1999, p. 153).

A "dupla articulação" do radical que designa a ideia de país à palavra paisagem, de acordo com Alain Roger (1997, p. 25), está presente na maior parte das línguas ocidentais: pays-paysage, na língua francesa, land-landscape 
no inglês, Land-Landschaft em alemão, landshap em holandês, landskap no sueco, landskal no dinamarquês, pais-paisaje no espanhol, paese-paesaggio no italiano. Diante disso, para o autor, "o país é o degrau zero da paisagem, que precede sua ideia como representação artística"4 (1997, p. 24). Essa dupla articulação à qual se refere Roger é também uma dualidade, que marca a compreensão do termo paisagem: a articulação ao radical que significa pais/território não é apenas linguística e, sim, politica, sendo assim resumida por Besse:

\begin{abstract}
A história política da paisagem pode ser caracterizada, de maneira sistemática, por uma tensão entre duas concepções e duas práticas concorrentes [...] de um lado, uma concepção cenográfica da paisagem, que acompanha e exprime a concepção do Estado moderno, entidade racional que se eleva às comunidades locais. Do outro lado, uma concepção 'local' da paisagem, compreendida como o lugar de vida de uma comunidade regida e regulada por costumes e que visa preservá-los (BESSE, 2014a, p. $114-115)$.
\end{abstract}

A paisagem na geografia, nos seus primórdios como ciência, carregava consigo o teor estético da paisagem pictórica, um certo encantamento com as belezas observadas em diversas partes do mundo. Humboldt e os demais geógrafos alemães, por exemplo, tinham o hábito de ilustrar seus trabalhos com gravuras, acrescentado às descrições objetivas observações pessoais em seus relatos. Afirmava-se, naquele contexto, a ideia de paisagem como vista, apresentando-a acima de tudo como um espetáculo visual, um panorama (BESSE, 2010, p. 265).

A partir do momento em que se assume como a disciplina acadêmica do estudo da paisagem ${ }^{5}$, a geografia tratou de abordá-la como conceito, correspondente, de forma geral, a "porções do espaço relativamente amplas, que se destacavam visualmente por possuírem características físicas e culturais suficientemente homogêneas para assumirem uma individualidade" (HOLZER, 1999, p. 151). O destaque dado à visualidade continuava presente, mas agora com o intuito de valorizar o senso de observação do geógrafo em campo e a sua capacidade em identificar "identidades espaciais" originadas da interface entre homens e natureza.

De acordo com Paul Claval (2004, p. 23), por volta dos anos 1900, eram muitos os geógrafos que definiam sua disciplina como uma ciência da paisagem ou das paisagens, como uma afirmação da particularidade do seu objeto de estudo frente a outras disciplinas que também se debruçavam 
sobre o conhecimento da superfície terrestre (CAPEL, 1891, p. 385 apud SALGUEIRO, 2001, p. 42). No entanto, o termo poderia não aparecer nos trabalhos de alguns dos seus principais expoentes como Ratzel, que privilegiou o território (Boden), e Vidal de La Blache, que destacava as regiões (pays), mas o sentido de paisagem estava presente, especialmente na identificação de porções de espaço bem definidas, de coerências próprias, nas quais os grupos tinham seus próprios "modos de vida", derivados de sua relação e adaptação ao meio. Ruy Moreira atribui esse não aparecimento explícito da paisagem a uma falta de clareza conceitual da época, mas reafirma a existência de um "sentido de fundamento" da paisagem naqueles estudos, atrelado ao olhar:

\footnotetext{
Talvez por isso, embora sendo central, a paisagem nunca apareça explícita em nenhum deles. O que se depreende é ser o aspecto visível do espaço e através do qual a ele se chega. A leitura da paisagem é o começo do itinerário do trabalho geográfico nos clássicos. E talvez por isso a descrição surja como um recurso de método por excelência. Mas o que a paisagem é conceitualmente difere de um clássico para outro [...]. A rigor, não os orienta um conceito, mas, isso sim, um certo sentido de fundamento. Isso quer dizer que o conceito de paisagem se confunde com a perspectiva do olhar. E tem por referência aquilo que nela e através dela se identifica [grifo nosso] (2011, p. 165).
}

Ainda nas primeiras décadas do século XX, Carl Sauer teria sido o maior difusor do conceito de paisagem, como afirma Holzer (1999, p. 153), destacando-o como termo central da ciência geográfica e traçando as bases da geografia cultural norte-americana. Para Sauer, a paisagem seria "uma área composta por uma associação distinta de formas, ao mesmo tempo físicas e culturais" (SAUER, 1998, p.23). Nesse entendimento de paisagem, é dado papel de destaque à cultura, compreendida como "a marca da ação do homem sobre a área" (SAUER, 1998, p. 30). O conteúdo da paisagem seria indissociável dos "fatos da cultura humana", à medida que esses influenciam as formas de uso das qualidades físicas das áreas. A consideração da cultura como "um fenômeno que se origina, difunde-se e evolui no tempo e no espaço, sendo compreensível no tempo, porém traçada no espaço onde se localiza" (CORRÊA, 1997, p. 269) continuaria a influenciar o arcabouço teórico da geografia cultural até a década de 1960, apesar do gradativo declínio desses estudos na Europa pós-segunda guerra, em face do esgotamento das análises regionais e da expansão da análise espacial. 
É a partir desse esgotamento dos estudos clássicos que ocorre um preterimento da paisagem na geografia e sua substituição, como ideia central dessa ciência, pelo conceito de espaço - considerado mais adequado para se entender geograficamente as transformações no mundo advindas do avanço do capitalismo pós-segunda guerra. Esse momento de privilégio do espaço como categoria central da geografia entre as décadas de 1950 e 1970 caracteriza a ascensão da Nova Geografia e, posteriormente, da vertente crítica (influenciada peta teoria marxista). Para a primeira, a paisagem ficava associada aos estudos físicos, designando a "expressão espacial dos ecossistemas" (SCHIER, 2003); já para a geografia crítica, a paisagem seria o reflexo das relações de reprodução do capitalismo, limitando-se a uma mera expressão material dessa dinâmica. Baseados nessa interpretação, surgiram alguns estudos os quais abordavam a paisagem e sua relação com a cultura de massa e sua apropriação como objeto de mercado, resultando em termos como "fetichismo da paisagem" e "paisagem como espetáculo" (popularizados especialmente após a publicação da revista Hérodote, por Yves Lacoste) (NAME, 2010, p. 171).

Concomitantemente a esse reaparecimento da paisagem nos trabalhos no âmbito da geografia crítica marxista, a corrente humanista inicia seu resgate conceitual a partir do embasamento fenomenológico. Apesar de ambas as correntes caracterizarem-se como movimentos de renovação do pensamento geográfico, no contexto de efervescência social, política e cultural da década de 1960 no mundo, quando nos referimos especificamente ao conceito de paisagem, foi a vertente humanista que avançou de forma mais significativa, visto que o maior diálogo e a aproximação com a fenomenologia proporcionaram um amadurecimento teórico-metodológico do qual carecia a paisagem da geografia tradicional e o qual as análises de cunho marxista não foram capazes de fornecer.

O resgate das obras dos geógrafos John Wright e Eric Dardel representaram o primeiro passo desse movimento na geografia humanista. Em seguida, autores como Yi-fu Tuan e Lowenthal passam a abordar a paisagem em seus trabalhos, ainda nos anos 1960 - antes da ampliação desses estudos na década seguinte. Esses primeiros trabalhos, no entanto, por vezes caracterizavam-se pelo predomínio de uma análise particularista, priorizando uma perspectiva essencialmente subjetiva (NAME, 2010, 
p. 172; SALGUEIRO, 2001, p. 44). Ainda naquele momento, o conceito de paisagem não teve centralidade nos estudos de base fenomenológica, visto que o lugar concentrava as atenções dos geógrafos dessa corrente.

Já no âmbito da geografia cultural, a partir dos anos 1970, muitos trabalhos passaram a adotar a paisagem como conceito central ${ }^{6}$, apresentando uma variedade de caminhos metodológicos para sua realização - às vezes fenomenológico, outras vezes propondo uma articulação deste ao método materialista histórico, outras vezes semióticos, semiológicos ou hermenêuticos. Essa variedade de metodologias nos estudos da corrente cultural, apesar de, em alguns casos, não proporcionar um aprofundamento das bases filosóficas na geografia, representou um importante avanço para a reincorporação da paisagem ao escopo teórico geográfico, a partir da busca por uma geografia dos significados e das intersubjetividades. Aqui é necessário pontuar que, mesmo no âmbito da geografia humanista, apesar de mais frequente, nem todos os trabalhos fundamentavam-se nos pressupostos fenomenológicos (MARANDOLA JR., 2013, p. 50). A fenomenologia, em muitos casos, era considerada uma diretriz, um posicionamento, mais do que um método em si.

Nas décadas seguintes, os estudos sobre paisagem seguiram ampliando as concepções e abordagens iniciadas pelos geógrafos culturais e humanistas na década de 1970, inserindo novas temáticas e aprofundando questões epistemológicas em torno do conceito. Em seu trabalho intitulado "O retorno da paisagem à Geografia", Jorge Gaspar (2001) cita algumas dessas perspectivas nos estudos paisagísticos, que dão ênfase às demais dimensões sensoriais da paisagem - paisagens olfativas (smellscapes), paisagens sonoras (soundscapes), paisagens do tato (landscapes of touch) -, assim como volta a atenção para outros componentes, como a memória (paisagens da memória/paisagens biográficas).

\section{Por uma filosofia da paisagem: caminhos fenomenológicos e a paisagem como experiência}

Nas constantes tentativas de reafirmar seu caráter científico, a geografia buscou se distanciar do imediato, do perceptível, do sensível, do descritível. 
Hoje, entendemos que esses são aspectos que nos permitem uma rica e profunda compreensão do espaço, ao contrário do que dariam a entender. A geografia humanista e a geografia cultural trouxeram de volta à ciência essas dimensões, substituindo, ao se tratar das paisagens, o olhar metódico do especialista que busca identificar e delimitar, por um olhar fluído, com sentidos diversos, que busca captar significados também diversos, presentes nos símbolos e experiências dos sujeitos com/no espaço.

Apesar dessa importante mudança teórico-metodológica nas abordagens da paisagem na geografia, notamos que o olhar permaneceu, de forma geral, como o sentido de fundamento do conceito, como afirmou Moreira ao se referir à paisagem na geografia clássica. A visualidade seria, dessa maneira, um pilar imutável na construção teórica da paisagem, resistente a todas as mudanças no pensamento geográfico?

Para tentarmos responder essa questão, acreditamos que o primeiro passo é ter como subsídio uma filosofia da paisagem ${ }^{7}$ e, mais especificamente, suas abordagens fenomenológicas, pois, ao considerarem a relação indistinta entre o que é visto e quem vê, nos abrem portas para outros aspectos no entendimento desse conceito, a partir das experiências que os sujeitos têm das paisagens. Essas experiências vão além da experiência da visão e "questionam sobre 'o ser na paisagem', o modo como os seres humanos estão no mundo e se ligam ao mundo através de seus corpos e suas sensibilidades" ${ }^{\prime \prime}$ (BESSE, 2010, p. 263 [grifo nosso]). Dessa forma, os estudos de orientação fenomenológica da paisagem, de acordo com Besse, resgatam a relação física e imediata com os elementos sensoriais do mundo, relegada pelos princípios da ciência moderna. A abertura dos aspectos materiais do mundo aos cinco sentidos e às emoções configurariam a paisagem como "ordem da experiência vivida, em termos da sensibilidade" (BESSE, 2010, p. 268).

A paisagem seria, assim, a experiência imediata do espaço, sem artifícios que a encobririam. Uma experiência do corpo, dos sentidos, que corresponderia, nas palavras de Besse, "à autenticidade e verdade do saber geográfico" (2014, p. 76). Para o autor, a paisagem precede toda orientação e referência e, por ser essa ausência de totalização, é experiência da proximidade das coisas (2014, p. 80). A presença e o envolvimento do homem na paisagem é o que une seus elementos e lhes dá significado, e, 
dessa forma, "a paisagem partilha da existência humana, colorindo e sendo colorida por ela" (RELPH, 1979, p. 14).

Sendo assim, a ligação dos elementos de uma paisagem se dá no próprio homem, e não fora dele, não existindo critérios predeterminados para a identificação e a delimitação das paisagens, como se essas fossem entidades independentes, passíveis apenas de reconhecimento. A "delimitação" de paisagens ocorre por meio do sentir, afirma Besse (2014), citando Strauss, e esse processo, muitas vezes, não pode ser racionalizado, assim como acontece com as experiências estéticas em relação às obras de arte. Mas, enquanto as obras de arte - incluindo a paisagem pictórica - estão no plano da representação, a paisagem é vivida, experienciada em nosso contato direto com a Terra: "muito mais que uma justaposição de detalhes pitorescos, a paisagem é um conjunto, uma convergência, um momento vivido" (DARDEL, 2015, p. 30).

$\mathrm{Na}$ contramão da tendência de modelização do espaço na geografia nos anos 1950, Eric Dardel desenvolveu uma abordagem fenomenológica para o estudo do espaço geográfico, dando ênfase ao caráter pré-científico da paisagem: "a paisagem se tonifica em torno de uma tonalidade afetiva dominante, perfeitamente válida, ainda que refratária a toda redução puramente científica" (2015, p. 31). Essa "tonalidade afetiva", à qual Dardel se refere, ou o "sentir", mencionado por Besse - entre outros conceitos e autores que seguem a abordagem fenomenológica -, muitas vezes abriu margens para críticas ao que seria uma geografia particularista. Por esse motivo, faz-se importante lembrar que as experiências de paisagem não se resumem unicamente a seu aspecto subjetivo, como bem resumido por Besse:

\footnotetext{
Pois a intimidade com o mundo com a qual estamos lidando aqui não é privada, não é voltada para dentro como para uma interioridade pessoal. Não é certo, além disso, que exista algo como "um interior" nesta história. A geografia vivida, isso é, o contato familiar com o mundo e o espaço, não é uma geografia interior, uma geografia da interioridade subjetiva, uma "paisagem da alma". Se a subjetividade está envolvida nessa experiência ou nessa geografia (duas palavras, talvez, para a mesma coisa), ela não é dobrada em si mesma, excluindo o mundo e o espaço. Ela é do espaço, mobilizada pelo espaço, movida no espaço, ela cruza o espaço. Ela está do lado de fora, no exterior (2010, p. 270) ${ }^{9}$.
}

Dessa maneira, devemos buscar a profundidade das paisagens não apenas nos seus significados individuais, mas, principalmente, no que 
conecta as experiências de paisagem dos sujeitos. Essa comunicação entre os mundos privados, como menciona Merleau-Ponty, só é possível através do mundo comum, o mundo sensível compartilhado por todos e em todos (2014, p. 23). Nas considerações do autor sobre mundo comum e mundo-da-vida, encontramos muitas referências à paisagem, pois, sendo experiência sensível, é experiência do espaço antes de qualquer representação ou elaboração. É um regresso às coisas mesmas, primeira lição fenomenológica, e é essa atitude natural e "antepredicativa" do mundo e da nossa vida, própria da experiência das paisagens, que nos fornece "o texto do qual nossos conhecimentos procuram ser a tradução em língua exata" (MERLEAU-PONTY, 1999, p. 16).

Essa atitude natural do mundo é anterior à reflexão, mas não separada do contexto da qual emerge: "sou eu que tenho a experiência da paisagem, mas nessa experiência, tenho consciência de assumir uma situação de fato, de juntar um sentido disperso nos fenômenos e de dizer o que eles querem dizer de si mesmos" (MERLEAU-PONTY, 1999, p. 355). De forma semelhante, Michel Collot afirma que, há, na paisagem, "essa apreensão sintética das relações que unem os elementos que a compõem" (2013, p. 23). Dessa maneira, a paisagem configura-se como "uma camada fundamental, um conjunto já pleno de um sentido irredutível: não sensações lacunares […" (MERLEAU-PONTY 1999, p. 47).

A complexidade das paisagens estaria no "jogo" entre o interno e o externo. Se, como afirma Besse, "no interior dessa clausura, a questão das relações com uma realidade mais vasta permanece" (2014, p. VIII), entendemos que a paisagem não é uma entidade fechada em si mesma. A experiência da paisagem não se fecha nesse primeiro contato sensorial com o espaço, ao contrário, se abre para o que não está visível naquele momento: "há, em primeiro lugar, essa parte invisível do espaço, que bordeja e extravasa constantemente o visível, e lembra o quanto a paisagem delimita um mundo e insinua em suas margens a presença de uma vida tumultuosa" (BESSE, 2014, p IX). A paisagem seria, assim, um convite para explorarmos "as dobras do visível".

A experiência da paisagem é, pois, abertura, e não fechamento, e esse talvez seja um dos aspectos mais importantes a destacar nessa breve reflexão sobre a paisagem como experiência do homem no espaço. Não à 
toa, muitos filósofos da paisagem convergem no entendimento da paisagem como horizonte. Citando Gibson, Michel Collot afirma que, para a fenomenologia, a paisagem é uma estrutura fundamental da percepção humana, "uma estrutura do horizonte que articula o visível e o invisível, o próximo e o distante" (2013, p. 21). Da mesma forma, para Besse, o longe e o perto marcam a "insistência do infinito no finito" (2014, p. IX), não havendo paisagem sem a coexistência do aqui e do além. A paisagem seria "escape para toda a Terra, uma janela sobre as possibilidades ilimitadas, um horizonte" (DARDEL, 2015, p. 31), e o horizonte, "o anúncio de uma promessa, um apelo" (BESSE, 2014, p. IX).

Essas considerações nos permitem compreender as paisagens em toda sua complexidade e em suas inúmeras possibilidades para pensarmos o mundo geograficamente. A partir de uma filosofia da paisagem e, mais particularmente, de sua abordagem fenomenológica enquanto experiência do espaço, entendemos a paisagem como portadora ou conteúdo da coexistência entre o perto e longe, o finito e o infinito. Paisagem abertura, paisagem horizonte. E nesses caminhos de abertura, seguiremos analisando trabalhos que questionam a predominância da visualidade como sentido fundante da paisagem, propondo novos elementos à sua reflexão.

\section{Um conceito em abertura: a paisagem além do visível}

De acordo com as abordagens fenomenológicas, a paisagem como experiencia corpórea indica envolvimento, experiencia física, contato através dos sentidos e do sentir, proximidade. Ainda assim, a questão da proximidade e do envolvimento nas paisagens parece-nos pouco explorada na geografia, devido à atribuição de centralidade à visualidade como condição própria do conceito. O foco no sentido da visão invariavelmente nos conduziu a que fossemos projetados para fora da paisagem, como se não fizéssemos parte do que vemos, como se ela estivesse apenas à nossa frente ou ao nosso redor, como se fosse possível olhar sem estarmos implicados nelas.

O predomínio desse olhar distanciado advém, como falamos, da origem do termo paisagem na Europa do século XV e de sua associação à 
representação artística da pintura, já tendo sido alvo de críticas por alguns autores, como Corbin: "a paisagem não se reduz a um espetáculo"10 (2001, p. 9); Serrão: "a incapacidade do homem moderno [...] levou-o por fim a tomar-se como um ser independente - podendo colocar a natureza à sua frente ou conceber-se a si próprio sem a natureza" (2013, p. 10); e Berque, para quem "o olhar recuado em relação às coisas"11 (1994, p. 22) levaria à compreensão de que a paisagem "está lá fora, à minha frente ou à minha volta"12 $^{12}$ (2016, p. 11).

Seria necessário desconsiderar esse vínculo entre paisagem e olhar, paisagem e visão? Não. Mas acreditamos que ele não dá conta de outras dimensões da experiência humana referentes às paisagens. É necessário que entendamos a paisagem para além do olhar ou, ainda, antes do olhar, pois estamos nas paisagens antes de vê-las, e isso redireciona a forma como as vivemos. Voltamos ao começo desse trabalho, ao trazermos novamente as palavras de Dardel: "a paisagem não é, em sua essência, feita para se olhar, mas a inserção do homem no mundo, [...] manifestação do seu ser com os outros, base do seu ser social" (2015, p. 32). Seguindo essa concepção, Besse afirma ser necessária uma nova definição de paisagem, que contemple a compreensão da presença humana e que considere aspectos como engajamento e implicação: a paisagem seria o meio no qual estamos implicados, estando integrada às nossas existências antes de ser uma imagem exterior:

Então, se a paisagem corresponde à nossa implicação no mundo, isso significa que ela não está longe de nós, no horizonte, já que, ao contrário, ela está próxima, que estamos em contato com ela, que ela nos envolve por assim dizer. Pode-se até chegar a dizer que é esse contato, esse conjunto de contatos com o mundo que nos rodeia, em suma essa experiência corporal, que faz a paisagem [grifo nosso] (BESSE, 2013, p. 12) ${ }^{13}$.

A compressão de que estamos envolvidos nas paisagens desloca a ideia de contemplação para a noção de implicação. As paisagens são, assim, "ambiências", o meio no qual estamos "mergulhados", segundo o autor. Esse sentido outro dado à paisagem faz com que atribuamos a ela papel em nossas existências pessoal e coletiva, em nossos valores da vida e na maneira de estar e habitar o mundo (BESSE, 2010, p. 245-246). Sendo assim, ainda de acordo com Besse, a paisagem é, fundamentalmente, "uma 
forma coletiva de habitar o espaço, habitar mundo, [...] como a casa dos homens, onde eles podem encontrar abrigo e identidade, isto é, significado para a sua existência"14 (2013, p. 8). Aqui se abre uma ampla perspectiva de estudo da paisagem centrada na ideia do habitar.

As noções de implicação e habitar reconfiguram a forma como significamos a paisagem em nossas vidas, no nosso cotidiano. Se a paisagem não é algo que está fora e se dela faço parte tanto quanto os elementos ao meu redor, há, aqui, a possibilidade de uma extensão do envolvimento e do cuidado que destinamos aos nossos corpos e à nossa existência, também às nossas paisagens, que, desde o século passado, são pensadas e produzidas para serem cada vez menos nossas, como se pertencessem a um sistema e a uma forma de produção inacessíveis à maioria das pessoas. Cada vez mais padronizadas e replicáveis, cada vez mais monumentais, assumindo semelhanças que podem ser identificadas em diferentes partes do mundo, as paisagens distanciam-se de nós, como se fossem elementos externos à nossa vida e pelos quais apenas passássemos.

Essas paisagens, as quais Edward Relph denomina paisagens modernas, são concebidas a partir de um "hiper planejamento que elimina qualquer possibilidade de mudança fundamental, reduzindo drasticamente as oportunidades dos indivíduos se envolverem com o local onde moram"15 (2016, p. 86). Para o autor, essas paisagens "negam sentimentos, ignoram a ética e diminuem a responsabilidade dos indivíduos sobre o ambiente no qual vivem"16 (RELPH, 2016, p. 64 - 65).

Como exemplos de paisagens modernas, Relph fala dos subúrbios norte-americanos e dos grandes centros financeiros, dentre outros exemplos, todos originados de processos de produção espacial caracterizados por um "autoritarismo ambiental benevolente"17 (RELPH, 2016, p. 99), isto é, quando a autoridade para fazer paisagens é destinada a um pequeno grupo de profissionais, retirando, dessa forma, a autonomia e a responsabilidade dos indivíduos sobre o espaço em que vivem. Esse processo vertical de pensar e construir paisagens dificulta a criação de laços de pertencimento aos lugares, propiciando uma gradativa "alienação do espaço", de acordo com Armand Frémont: "o homem, um estranho para si mesmo e para os outros, torna-se também, estranho ao espaço onde vive"18 (FRÉMONT, 1999, p. 249). 
É nesse contexto - no qual predomina a visualidade ostensiva que esconde o vazio que a preenche e que esmaga as manifestações autênticas de vida - que temos o surgimento das paisagens sem-lugar. De acordo com Relph, nestas paisagens, as diferenças passam a ser relacionadas mais às marcas e nelas "a perda da diversidade e da identidade geográficas foi palpável, expressa na perda da continuidade histórica" (RELPH, 2012, p. 20).

Entender a supressão e a ausência da lugaridade ${ }^{19}$ (placelessness) nas paisagens é fundamental quando consideramos, de acordo com Relph, que o lugar diz respeito às maneiras como os seres humanos se relacionam com o mundo, a partir da ideia de autenticidade e do envolvimento dos sujeitos com seu mundo coletivo imediato (MARANDOLA JR., 2016, p. 11). Quando falamos em autenticidade, nos referimos a uma "experiência direta e genuína de todo o complexo da identidade dos lugares" (RELPH 1976, p. 64 apud MARANDOLA JR, 2016, p. 11), o que, por sua vez, também está relacionada às experiências das paisagens, já que essas são, igualmente, formas de nos relacionarmos com o mundo. O autoritarismo ambiental benevolente e a consequente alienação do espaço promovem uma mediação entre os sujeitos e seus lugares e paisagens, interferindo em sua autenticidade ao enquadrar as possibilidades reais de experiência em formas pré-estabelecidas, limitando "as possibilidades do ser". Segundo Marandola Jr:

As experiências são estas possibilidades que na tendência de homogeneização e fixação de padrões comportamentais e construtivos, as limitam e as tornam previsíveis e mediadas. E isso é feito substancialmente pelo controle da forma dos lugares, de sua construção e da manipulação das identidades pela estrutura física, as atividades e os significados que ali podem ser experienciados (MARANDOLA Jr. 2016, p. 14).

No trecho em destaque, podemos observar o quanto o controle da paisagem (subtendida como formas e estrutura física) pode ser determinante na experiência espacial dos sujeitos e, consequentemente, na atribuição de significados que é dada aos lugares. Uma paisagem engessada, padronizada, supervisionada, moldada por interesses externos à realidade vivida, é uma forma de repressão à experiência e à criação de familiaridade a partir da vivência dos lugares. Como afirma Marandola Jr, "limitar as formas dos lugares, portanto, é limitar o próprio ser humano" (2016, p. 14). 
O entendimento das paisagens e lugares, assim como das regiões, de acordo com Angelo Serpa, deve encaminhar-se para a desalienação espacial, reafirmando o sentido de um espaço vivido a partir "das várias maneiras através das quais conhecemos e nos relacionamos intencionalmente com o mundo, enquanto sujeitos individuais e coletivos" (SERPA, 2013, 176). Enquanto espaços vividos, paisagens, lugares e regiões são espaços relacionais, "modos geográficos de existência", constituindo a unidade do ser no mundo (SERPA, 2013, p. 176). Essa compreensão, para o autor, nos conduz a uma "geografia humana dos espaços vividos", que nos auxilia a pensar o espaço e as paisagens "nas experiências populares, filosofias espontâneas e histórias vividas” (2013, p. 183).

Compreender as paisagens como modo de nos relacionarmos com o mundo ou, ainda, como mundo-vivido geográfico (RELPH, 1979, p. 7), compartilhado com os outros, traz à luz a relação indissociável entre paisagem e intersubjetividade, e, nesse sentido, segundo Serpa, "a paisagem se constitui de mundo e transcendências sempre negociadas" (2019, p. 30). Sendo assim, para o autor, uma fenomenologia/ontologia existencialista da paisagem perpassa diferentes horizontes e escalas, sempre vividos no cotidiano (SERPA, 2019, p. 31).

Essas considerações reafirmam a necessidade de pensarmos a paisagem enquanto dimensão do espaço vivido - experiência compartilhada e parte do nosso ser no mundo. Nesse sentido, o entendimento da paisagem como forma-de-vida, trazido por Marandola Jr. (2017) com base na filosofia de Giorgio Agamben, nos apresenta uma perspectiva política da paisagem ou, ainda, a paisagem como experiência política (MARANDOLA JR., 2017, p. 48). As formas-de-vida relacionam-se aos modos de se viver, sendo a vida sem forma uma vida nua, de acordo com Agamben. Pensar a paisagem a partir dessa perspectiva torna-se possível através das abordagens fenomenológicas, que não separam sujeitos e espaços, fazendo com que, dessa maneira, a paisagem não seja entendida apenas como forma, mas, sim, componente das formas-de-vida, corporificada nas pessoas:

A paisagem, neste sentido, é igualmente componente das formas-de-vida, mas não como cenário ou contexto pré-existente. A paisagem também possui um sentido ontológico, que remete ao ser e que nos permite pensar que a paisagem não é apenas o completo exterior, mas é também a interioridade. Mais do que 
isso, como forma-de-vida, ela também está corporificada nas pessoas da paisagem (MARANDOLA JR., 2017, p. 41).

A experiência política da paisagem, segundo Marandola Jr., ocorre na exposição e na abertura aos sentidos, que vão do individual ao comum (já que a paisagem é experiência compartilhada), do individual ao político. A paisagem é forma-de-vida em exposição, cuja possibilidade de transformação é potência. Considerando a paisagem como forma-de-vida e parte de nossa existência no mundo, o sentido político do "ser em potência" mistura-se com o sentido da paisagem, fazendo com que seja possível afirmar que, além de estarmos nela, somos-paisagem (MARANDOLA JR., 2017, p. 42).

Sendo assim, muito mais do que o que vemos, e mais do que onde estamos, a paisagem somos nós (MARANDOLA JR., 2017, p. 42), como dimensão geográfica da existência cujo sentido político perpassa pela abertura às experiências comuns. A paisagem só existe com os outros, em nós e fora de nós - mas não como cenário, e, sim, como experiência sensorial, material e afetiva do mundo vivido e compartilhado. É por essa mistura, de acordo com Besse, que a paisagem é experiência de travessia e imersão:

Longe de ser um objeto espetacular situado diante de um sujeito, a paisagem é a experiência de uma travessia, ou ainda, de uma imersão que atinge o corpo e o põe em um certo estado [...] uma certa disposição afetiva face ao mundo que o envolve, e que, sobretudo, Ihe conduz a viver e estar no mundo, ou seja, o habitar, de diferentes maneiras. A paisagem é habitar o mundo e ser habitado por ele ${ }^{20}$ (BESSE, 2018, p. 59 - 50).

Para Besse, ao estudarmos as paisagens, a pergunta inicial que devemos nos fazer não é de cunho estético, mas "quais possibilidades oferece a paisagem para o ser humano viver, para ser livre, para estabelecer relações com outros e com a própria paisagem?", ou "qual a contribuição da paisagem para a realização pessoal e mudança social?" (2014a, p. 36). A busca do sentido das paisagens deve incluir as formas pelas quais elas tornam o mundo habitável para o homem.

Dessa maneira, buscamos compreender as paisagens não como porta de entrada para algo que está além, acessada a partir da visão. A paisagem se desdobra não em algo exterior, mas nela mesma, enquanto base de nossa 
existência, contatos e sensações não mediadas do/com o mundo. Como diz Besse, antes de ver a paisagem eu tenho meus pés fixados nela, eu estou nela. Esse entendimento nos sinaliza caminhos para pensarmos a paisagem como forma de habitar, forma-de-vida, experiência política, espaço vivido e criado, que nos exige engajamento e implicação muito além do olhar. Porque somos criadores das paisagens que nos chega aos sentidos, elas são parte de quem somos, enquanto indivíduos e coletividades. É preciso, então, nos desalienarmos da paisagem como coisa externa, que acessamos apenas pela visão, e nos colocarmos de volta nas paisagens, enquanto nosso modo de existência e comunicação com o mundo e com os outros. Se assim entendo a paisagem, assim a vivo, assim me permito ir além, ao mesmo tempo em que me finco em meus sentidos (no que sinto, no que toco, no que percebo, no que vejo), em um movimento permanente de abertura.

\section{Notas}

1 DARDEL, Eric. 2015, p. 32 (tradução de Werther Holzer).

2 Tradução nossa do original: "What mattered for the designation was that these were regions in which customary law, determined in various ways by the Community living and workingin a area, extended over and defined the territorial limits of the Land. "Custom and culture defined a Land, not physical geographical characteristics - it was a social entity that found physical expression in the area under its law. The unity of fellowship and rights within the community and the space over which fellowship and rights held sway constituted the Landschaft".

3 Tradução nossa do original: "As these various associations suggest, and the word 'prospect' makes clear, landscape privileges the sense of sight, and what started as a representation of space rapidly became a designation of material spaces themselves, which were referred to as landscapes and viewed with the same distanciated and aesthetically discriminating eye that had been trained in the appreciation of pictures and maps. A landscape is seen, either framed within a sketch or painting, composed within the borders of a map, or viewed from a physical eminence through receding planes of perspective".

4 Tradução nossa do original: "Le pays, c'est, de quelque sorte, le degré zéro du paysage, ce que précède son artialization".

5 A ideia de que a "essência da geografia reside na análise das paisagens" (tradução nossa do original "l'essence de la géographie réside en l'analyse des paysages") marcou profundamente a imagem da geografia para as disciplinas vizinhas, de acordo com Berque (2001, n.p.).

6 Dentre esses trabalhos, podemos destacar aqueles realizados por dois principais grupos à época: o da geografia cultural anglófona, denominada New Cultural Geography, que teve entre seus principais autores nomes como Denis Cosgrove, James Duncan, Stephen Daniels, Peter Jackson, Donald Meinig, entre outros; e o dos geógrafos franceses, cuja abordagem cultural da paisagem foi muito influenciada pela concepção de espaço vivido, de Armand Frémont (SALGUEIRO, 2001, p. 45; CLAVAL, 2003, p. 11). Entre os seus principais autores, destacamos Paul Claval, Augustin Berque, Roger Brunet e o filósofo Alain Roger. 
7 Entre os autores que se dedicaram ao tema, além dos que mencionamos neste trabalho, como Michel Collot, Augustin Berque, Jean-Marc Besse e Eric Dardel, destacamos George Simmel e sua obra Filosofia da Paisagem (Philosophie der Landschaft), publicada originalmente em 1913.

8 Tradução nossa do original:"Elles s'interrogent sur "l'être au paysage ", sur la manière dont les êtres humains sont au monde, et se rattachent au monde par leur corps et leur sensibilité".

9 Tradução nossa do original: "Car l'intimité avec le monde dont il s'agit ici n'est pas privée, elle n'est pas repliée sur elle-même comme sur une intériorité personnelle. Il n'est pas sûr, d'ailleurs, qu'il y ait quelque chose comme "un intérieur " dans cette histoire. La géographie vécue, c'est-à-dire le contact familier avec le monde et l'espace, n'est pas une géographie intérieure, une géographie de l'intériorité subjective, un "paysage de l'âme". Si la subjectivité est impliquée dans cette expérience ou cette géographie (deux mots, peut-être, pour la même chose), elle n'est pas repliée sur elle-même à l'exclusion du monde et de l'espace. Elle est de part en part spatiale, mobilisée par l'espace, déplacée dans l'espace, elle traverse l'espace. Elle est dehors, à l'extérieur".

10 Tradução nossa do original: "Mais le paysage ne se réduit pas à un spetacle".

11 Tradução nossa do original: "Un regard qui prend du recul par rapor aux choses (...)".

12 Tradução nossa do original: "Le paysage en principe, est là-dehors, devant moi ou autour de moi (...)".

13 Tradução nossa do original: "Alors, si le paysage correspond à notre implication dans le monde, cela veut dire qu'il n'est pas loin de nous, à l'horizon, puisqu'au contraire il est proche, que nous sommes à son contact, qu'il nous enveloppe pour ainsi dire. On pourrait même aller jusqu'à dire que c'est ce contact, cet ensemble de contacts avec le monde environnant, bref cette expérience corporelle, qui fait paysage, qui fait le paysage".

14 Tradução nossa do original: "le paysage est défini de manière fondamentale comme une manière collective d'habiter l'espace, d'habiter le monde. Le paysage est défini comme demeure des hommes où ceux-ci peuvent trouver abri et identité, c'est-àdire sens pour leur existence".

15 Tradução nossa do original: "(...) as hyperplanning, arranging things just so, eliminating the possibility of fundamental change, and drastically reducing the opportunities for indivuduals to become involved with their suburbian places".

16 Tradução nossa do original: “(...) that modern landscape-making (...) denies feelings, ignores ethics and minimises the responsibility of individuals for the environments in which they live".

17 Tradução nossa do original: "benevolent environmental authoritarianism".

18 Tradução nossa do original: "L'homme, étranger à lui-même, et aux autres, devient aussi étranger à l'espace où il vit".

19 Tradução de Eduardo Marandola Jr. para o termo placelessness, de Edward Relph.

20 Tradução nossa do original: "Loin d'être un objet spetaculaire posé face à un sujet, le paysage est l'expérience d'une traversée ou plutôt d'une immersion qui agite en quelque sorte le corps el le met dans un certain état (...), une certaine disposition affective vis-a-vis du monde environnant, et qui, surtout, le conduit à vivre et à se tenir dans le monde, c'est à dire à l'habiter, de telle ou telle façon. Le paysage c'est habiter le monde et être habité par lui".

\section{Referências}

BERQUe, Augustin. Paisage, milieu, histoire. In: BerQUe, A (Org.). Cinq propositions pour une théorie du paysage. Seyssel: Champ Vallon, 1994. p. 5-10. 
BERQUE, Augustin. La paysage Zon Bing. Paysage et dépassement de la modernité. Les visions du paysage. Actes du Colloque de Liège, 2001. Disponível em : http://www.oeuvresouvertes.net/autres_espaces/berque1.html Acesso em: nov. 2018.

BERQUE, Augustin. La pensée paysagère. Batia: Éditions Éoliennes, 2016.

BESSE, Jean-Marc. Le paysage, espace sensible, espace public. Meta: Research in hermeneutics, phenomenology, and practical philosophy, v. II, n. 2, p. 259-286, / 2010. Disponível em: http://www.metajournal.org/articles_pdf/259286-jm-besse-meta4-tehno.pdf Acesso em: nov. 2018.

BESSE, Jean-Marc. Conference Paysage et projet. 2013. Disponível em: http:// terresenvilles.org/wpcontent/uploads/2016/11/TEV_CH2.2_ActesBesse_2013. pdf Acesso em: out. 2018.

BESSE, Jean-Marc. Ver a Terra: seis ensaios sobre a paisagem e a geografia. São Paulo: Perspectiva, 2014.

BESSE, Jean-Marc. $\mathbf{O}$ gosto do mundo: exercícios de paisagem. Rio de Janeiro: EduUERJ, 2014a.

BESSE, Jean-Marc. La necessité du paysage. Marseille: Paranthèses, 2018.

CLAVAL, Paul. A evolução recente da geografia cultural de língua francesa. Geosul, Florianópolis, v. 18, n. 35, p. 7-25, jan./jun. 2003.

CLAVAL, Paul. A Paisagem dos geógrafos. In: CORRÊA, Roberto Lobato; ROSENDAHL, Zeny (Org.). Paisagens, textos e identidades. Rio de Janeiro: EDUERJ, 2004. p. $13-74$.

COLLOT, Michel. Poética e filosofia da paisagem. Rio de Janeiro: Editora Oficina Raquel, 2013.

CORBIN, Alain. L'homme dans le paysage. Paris: Les editions Textuel, 2001. CORRÊA, Roberto Lobato. Carl Sauer e a Geografia Cultural. In: CORREA, Roberto Lobato. Trajetórias Geográficas. Rio de Janeiro: Bertrand Brasil, 1997.

COSGROVE, Denis E. Landscape and landschaft. (lecture delivered at the "spatial turn in history" symposium) German historical institute, february 19 , 2004.

DARDEL, Eric. O homem e a terra. São Paulo: Perspectiva, 2015.

FREMONT, Armand. La région espace vécu. 12. ed. Flammarion, 1999.

GASPAR, Jorge. O retorno da paisagem à Geografia: apontamentos místicos. Finisterra - Revista Portuguesa de Geografia, XXXVI, 72, p. 83-99, 2001. 
HOLZER, Werther. Paisagem, imaginário, identidade: alternativas para o estudo geográfico. In: CORRÊA, Roberto Lobato; ROSENDHAL, Zeny (Org.). Manifestações da cultura no espaço. Rio de Janeiro: EdUERJ, 1999. p. 149168.

MARANDOLA JR, E. Fenomenologia e pós-fenomenologia: alternâncias e projeções do fazer geográfico humanista na geografia contemporânea. Geograficidade, v. 3, p. 49-64, 2013.

MARANDOLA JR, E. Identidade e autenticidade dos lugares: O Pensamento de Heidegger em Place and Placelessness, de Edward Relph. Geografia, Rio Claro, v. 41, n. 1, p. 5-15, jan./abr. 2016.

MARANDOLA JR, E. Morte e vida do lugar: experiência política da paisagem. Pensando - Revista de Filosofia, v. 8, n. 16, 2017.

MERLEAU-PONTY, Maurice. Fenomenologia da percepção. 2. ed. São Paulo: Martins Fontes, 1999.

MERLEAU-PONTY, Maurice. O visível e o invisível. São Paulo: Perspectiva, 2014. MOREIRA, Ruy. 0 pensamento Geográfico brasileiro vol 1: As matrizes clãssicas. 2. ed. São Paulo: Contexto, 2011.

NAME, Leo. O conceito de paisagem na geografia e sua relação com o conceito de cultura. GeoTextos, v. 6, n. 2, p. 163-186, dez. 2010.

RELPH, Edward. As bases fenomenológicas da Geografia. Geografia, Rio Claro, v. 4, n.7, p. 1-25, 1979.

RELPH, Edward. Reflexões sobre a emergência, aspectos e essência de lugar. In: MARANDOLA JR., Eduardo; HOLZER, Werther; OLIVEIRA, Lívia (Org.). Qual o espaço do lugar? Geografia, Epistemologia, Fenomenologia. São Paulo: Perspectiva, 2012. p. 17-32.

RELPH, Edward. Rational Landscapes and Humanistic Geography. Routledge, 2016.

ROGER, Alain. Court traité du paysage. Éditions Gallimard, 1997.

SALGUEIRO, Teresa B. Paisagem e Geografia. Finisterra - Revista Portuguesa de Geografia, v. XXXVI, n. 72, p. 37-53, 2001.

SAUER, Carl O. A morfologia da paisagem. In: CORRÊA, Roberto Lobato; ROSENDAHL, Zeny (Org.). Paisagem, tempo e cultura. Rio de Janeiro: EdUERJ, 1998 [1925]. p. 12-74.

SCHIER, R. A. Trajetórias do conceito de paisagem na geografia. RA'E GA, n.7, p.79-85, 2003. 
SERPA, Angelo. Paisagem, lugar e região: perspectivas teórico-metodológicas para uma geografia humana dos espaços vividos. GEOUSP - espaço e tempo, São Paulo, n. 33, p. 168- 185, 2013.

SERPA, Angelo. Por uma geografia dos espaços vividos: Geografia e Fenomenologia. São Paulo: Contexto, 2019.

SERRÂO, Adriana V. Paisagem: natureza perdida, natureza reencontrada? Revista de Filosofia Moderna e Contemporânea. Brasília, n. 2, p 7-27, 2013.

Recebido em: 16/10/2019

Aceito em: 01/11/2019 